\title{
Comfortably Engaging: Which Approach to Alcohol Screening Should We Use?
}

\author{
Daniel C. Vinson, MD, MSPH \\ James M. Galliher, $P b D^{2}$ \\ Carol Reidinger, $M S^{1}$ \\ Jennifer A. Kappus, BA ${ }^{2}$ \\ 'The Center for Family Medicine Science, \\ Department of Family and Community \\ Medicine, University of Missouri-Columbia, \\ Columbia, Mo
}

${ }^{2}$ AAFP National Research Network, American Academy of Family Physicians, Leawood, Kan
Conflict of interest: none reported

\section{CORRESPONDING AUTHOR}

Daniel C. Vinson, MD, MSPH

The Center for Family Medicine Science

Department of Family and Community

Medicine

M231 Health Sciences

University of Missouri-Columbia

Columbia, MO 65212

VinsonD@health.missouri.edu

\begin{abstract}
PURPOSE We wanted to compare 2 screening instruments for problem drinking, the CAGE and a single question, assessing frequency of use, patient and clinician comfort, and patient engagement in change.
\end{abstract}

METHODS The study was a crossover, cluster-randomized clinical trial with 31 clinicians in Missouri and 13 in the American Academy of Family Physicians (AAFP) National Network for Family Practice and Primary Care Research; 2,800 patients provided data. The clinician was the unit of randomization. Clinicians decided whether to screen each patient; if they chose to screen, they used the screening approach assigned for that block of patients. The clinician and patient separately completed questionnaires immediately after the office visit to assess each one's comfort with screening (and any ensuing discussion) and the patient's engagement in change.

RESULTS Missouri clinicians screened more patients when assigned the single question (81\%) than the CAGE (69\%, P = .001 in weighted analysis). There was no difference among AAFP network clinicians (96\% of patients screened with the CAGE, $97 \%$ with the single question). Eighty percent to $90 \%$ of clinicians and $70 \%$ of patients reported being comfortable with screening and the ensuing discussion, with no difference between approaches in either network. About one third of patients who were identified as problem drinkers reported thinking about or planning to change their drinking behavior, with no difference in engagement between screening approaches.

CONCLUSIONS Clinicians and patients reported similar comfort with the CAGE questions and the single-question screening tools for problem drinking, and the 2 instruments were equal in their ability to engage the patient. In Missouri, the single question was more likely to be used.

Ann Fam Med 2004;2:398-404. DOI: 10.1370/afm.83.

\section{INTRODUCTION}

$\Lambda^{1}$ cohol problems are common, $15 \%$ of US adults have had 5 or more drinks on at least one occasion in the past month (hazardous drinking), ${ }^{1}$ and $7.4 \%$ met the diagnostic criteria in the fourth edition of the Diagnostic and Statistical Manual of Mental Disorders ${ }^{2}$ for current alcohol abuse or dependence. ${ }^{3}$ Many randomized clinical trials have shown that brief interventions are effective in helping problem drinkers reduce their consumption to safe levels. ${ }^{4-6}$

Alcohol problems-defined in this report as hazardous drinking ${ }^{7}$ and/or current alcohol abuse or dependence ${ }^{2}$ - meet the criteria for a condition for which routine screening is appropriate. ${ }^{8}$ Many screening tests are available, ${ }^{9}$ including the CAGE questions ${ }^{10}$ and a recently validated single question (Table 1), ${ }^{11}$ which are similar in sensitivity and specificity.

Previous studies ${ }^{12-15}$ have shown that screening for alcohol problems is not routine in primary care. The barriers to screening include clinicians' discomfort with addressing alcohol consumption when it is not on the patient's agenda. ${ }^{16} \mathrm{~A}$ screening approach that is shorter or more comfort- 


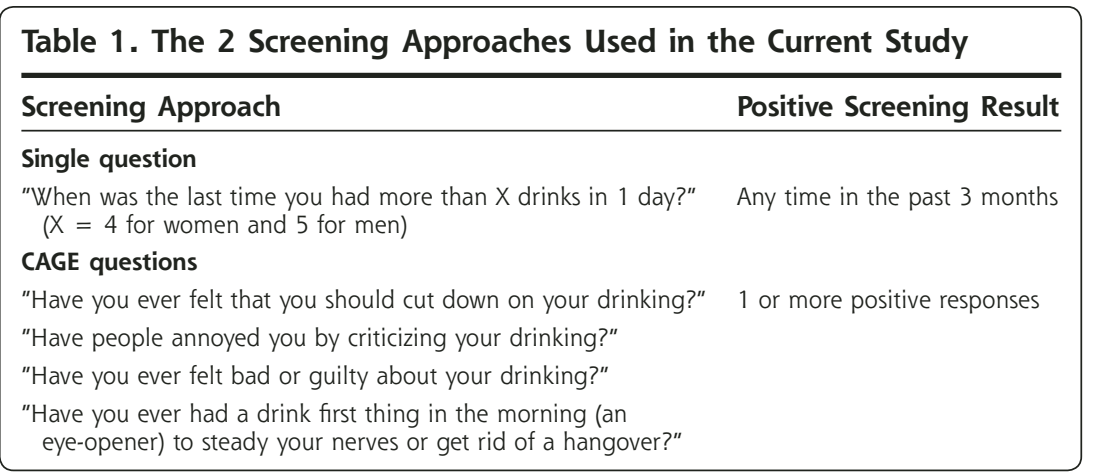

to clinicians include its ease of use, brevity, comfort for the clinician, and comfort for patients. Patient comfort may affect clinician acceptance, because a screening tool that is uncomfortable for patients might provoke resistance on their part, leading clinicians to be less inclined to use it again. Importantly, screening approaches might differ in how effectively they engage problem drinkers in moving toward change. A more engaging instrument, even if less sensitive or specific, might help a greater proportion of problem drinkers change their behavior than a more sensitive and specific, but less engaging, instrument. We designed the current study to address these issues.

\section{METHODS}

The study was a cluster-randomized, crossover, nonblinded clinical trial using the clinician as the unit of randomization. Allocation of patients to screening approach was not concealed from clinicians, because a primary research goal was to find out which approach they would use more frequently.

Family physicians, physician assistants, and nursepractitioners were recruited from Missouri practices; 31 participated. Most worked at University of Missouri-Columbia clinics, including Student Health, or at university-affiliated rural practices. Two other residency programs in Missouri participated, Cox in Springfield and Baptist Lutheran in Kansas City. Eight invited physicians declined to participate. Of 174 clinicians in the American Academy of Family Physicians (AAFP) National Network for Family Practice and Primary Care Research, 13 participated. Clinicians who participated had been in their current practice longer (13.5 years) than clinicians who did not ( 8.2 years, $P=.01)$, but there were no other significant differences in demographic or practice characteristics.

A response to the single-question screening tool (Table 1) was considered to be positive if the patient answered with any time in the last 3 months. A response to the CAGE was considered to be positive if 1 or more answers were affirmative, choosing a threshold that would maximize sensitivity. ${ }^{10}$ The 4 CAGE questions can be focused on the past year or a lifetime reference can be assumed, ${ }^{21}$ which was its original design. ${ }^{22}$ In the Missouri network, we used a lifetime frame of reference (herein labeled "ever" positive). In the AAFP national network, clinicians asked patients who had a positive CAGE response, "Has this occurred 
during the past year?" allowing us to examine separately those patients who had a positive response in the past year on the CAGE questionnaire from those who were ever had a positive response.

Each clinician was randomized to use one screening approach (CAGE or single question), then the other. In Missouri each approach was used for 2 days. In the AAFP network, each was used for 30 consecutive patient encounters. Patients 18 years old and older who gave oral informed consent were eligible to participate. Patients were excluded if they were severely ill, cognitively impaired, or were unable to read English. The patient questionnaire was available in Spanish if requested by the clinician, but none did. Patient literacy was not tested.

During each encounter with a participating patient, clinicians provided whatever care they would ordinarily have provided. In addition, they decided whether to screen for problem drinking. The mere presence of the data forms encouraged them to screen, but they were asked to use their clinical judgment when deciding whether to screen. If screening was conducted, the clinician used the assigned approach and recorded the patient's answers on the clinician questionnaire, an 8.5 $\times 3.7$-in card. Immediately after the visit, the clinician answered an additional 6 questions on the card, including the length of the alcohol discussion, the clinician's comfort and patient's openness during the discussion, and what the clinician did if the response to the screening test was positive.

The patient completed a separate questionnaire immediately after the encounter regardless of whether screening occurred and whether alcohol was mentioned. The patient questionnaire asked about the patient's comfort with screening and any ensuing alcohol-related discussion, their estimate of how long that discussion (if any) lasted, their plans (if any) for changing their drinking, and the 10-item Alcohol Use Disorders Identification Test (AUDIT), ${ }^{23}$ a screening instrument we used in this study as a self-reported criterion standard to identify hazardous or harmful drinking. AUDIT scores range from 0 to 40 . The standard threshold for identifying problem drinking is a score of 8 or greater, ${ }^{23}$ though thresholds as low as 5 have been used. ${ }^{24}$ Clinicians did not see patients' questionnaire answers, nor did they know the patients' AUDIT scores.

Patients were clustered by clinician. If we assumed that patients had been selected by simple random sampling, the variance could be substantially underestimated. ${ }^{25}$ To account for that cluster- ing, we used the hierarchical modeling commands in Stata, using the clinician as the primary sampling unit. ${ }^{26}$ Because the frequency of screening was not normally distributed across clinicians, we used nonparametric analyses, including Spearman $\rho$ correlation coefficients and the Mann-Whitney U test to compare continuous variables across groups.

Study approval was obtained from the institutional review boards of the University of Missouri Health Science Center and other participating centers. Clinicians not affiliated with an institutional review board were approved through the University of Missouri as unaffiliated investigators. All patient data were anonymous; the clinician and patient questionnaires from a given office visit were linked by a study identification number and not by patient name.

\section{RESULTS}

The 31 Missouri clinicians approached 2,577 patients, and 2,134 (83\%) participated. Missing data varied by questionnaire item; the items most commonly missing were AUDIT questions. Of the 2,134 patients who enrolled, 1,739 (81\%) answered all 10 AUDIT questions. The 13 AAFP national network clinicians approached 767 patients, and $666(87 \%)$ participated. Of the 666 who enrolled, 595 (89\%) answered all 10 AUDIT questions. Demographic information and prevalence of positive AUDIT scores are displayed in Table 2.

In Missouri, the clinicians screened $81 \%$ of the patients assigned to the single question and $69 \%$ with the CAGE $(P=.001$, taking cluster sampling into account). In the AAFP network, almost all patients assigned to either approach were screened $(96 \%$ with the CAGE, $97 \%$ with the single question, $P=.5$ ).

\begin{tabular}{|lcc|}
\hline \multicolumn{3}{c}{ Table 2. Demographic Information and Prevalence of a Positive } \\
Alcohol Use Disorders Identification Test (AUDIT) & Score \\
\hline & $\begin{array}{c}\text { Missouri } \\
\text { Network }\end{array}$ & $\begin{array}{c}\text { AAFP National } \\
\text { Network }\end{array}$ \\
Characteristics & 31 & 13 \\
\hline Participating clinicians, $n$ & 2,577 & 767 \\
Patients approached, $n$ & $231(9)$ & $55(7)$ \\
Refused (of those approached), n (\%) & $139(5)$ & $42(5)$ \\
Not eligible, n (\%) & $73(3)$ & $4(1)$ \\
Missed, n (\%) & $2,134(83)$ & $666(87)$ \\
Patients participating (\% of those & & $595(89)$ \\
approached), n (\%) & $1,739(81)$ & 62 \\
Complete data (\% of enrolled), n (\%) & 67 & $52(17)$ \\
Female patients, \% & $43(18)$ & $39-64$ \\
Age, mean y (SD) & $27-53$ & 12 \\
Interquartile range, y & 17 & 6 \\
Patients with an AUDIT score $\geq 5, \%$ & 8 & \\
Patients with an AUDIT score $\geq 8, \%$ & & \\
\hline
\end{tabular}




\section{Patient and Clinician Comfort}

Patients and clinicians rated the comfort of the 2 screening approaches and ensuing discussions similarly in both networks (Table 3). On an ordinal scale in which 1 is "very uncomfortable" and 5 is "very comfortable," patients in both networks rated their comfort as 4.2 with either screening approach. The 95\% confidence intervals (CIs) were the same for both approaches in a given network, 4.1-4.4 in the AAFP network, 4.1-4.3 in Missouri, with adjustment for clustering by clinician.

Patients' AUDIT scores were inversely correlated with their self-reported level of comfort (Spearman $\rho$ $-0.18, P<.001)$. Patients with a positive AUDIT score averaged 4.0 on a 5 -point scale in both networks with either screening approach.

Clinicians' assessments of their own comfort and their patients' openness to discussing alcohol were also inversely correlated with the patient's AUDIT score $(P \leq .02)$. The correlation coefficients, however, were small, with values of Spearman $\rho$ of -0.09 to -0.11 for both comparisons in each network.

\section{Duration of Alcohol-Related Discussions}

As reported by the clinicians, the duration of the alcohol-related conversations (screening, if done, plus ensuing discussion, if any) was similar with the 2 approaches. In both networks, the conversations were shorter with the single question than with the CAGE questions, but the difference was small and not statistically significant when clustering by clinician was taken into account. On an ordinal 5-point scale (less than 30 seconds, 30 to 60 seconds, 1 to 2 minutes, 2 to $4 \mathrm{~min}$ utes, longer than 4 minutes), the mean among AAFP clinicians (adjusted for clustering) was 1.5 minutes with the CAGE (95\% CI, 1.3-1.7 minutes) and 1.4 minutes with the single question (95\% CI, 1.2-1.6 minutes). In Missouri, the mean rating of duration for the CAGE was 1.7 minutes (95\% CI, 1.6-1.9 minutes); for the single question it was 1.7 minutes (95\% CI, 1.5-1.9 minutes). The proportion of alcohol-related discussions that lasted less than 60 seconds was similar within each network: 94\% with the CAGE and 93\% with the single question in the AAFP network; and $83 \%$ and $82 \%$, respectively, in Missouri.

Clinicians spent more time talking about alcohol with patients who had a positive response to the screening test than those who had a negative response, but most alcohol-related discussions were still short. Clinicians reported that the discussion was less than $1 \mathrm{~min}$ ute with $67 \%$ of patients who had a positive screening test response in the AAFP network and with $57 \%$ of such patients in Missouri, with no significant difference between screening approaches in either network.

As reported by patients, the duration of the alcohol-related conversations was slightly longer with the CAGE than with the single question, 1.7 vs $1.6 \mathrm{~min}$ utes, using the same ordinal scale that clinicians used, in both networks. This difference was significant in the Missouri network, adjusted for clustering.

\section{Prevalence of a Positive Screening Test Response}

Of patients screened with the CAGE in the AAFP network, $8 \%$ had a positive response using the past-year time frame and $16 \%$ had a positive response using a lifetime frame; of those screened with the single question, $14 \%$ had a positive response. In Missouri, $22 \%$ of the patients had a positive response with either approach, using a lifetime frame of reference for the CAGE.

Using an AUDIT score of 5 or greater to identify patients who might have 


\begin{tabular}{|c|c|c|c|c|}
\hline \multirow[b]{2}{*}{ Stage of Change ${ }^{27}$} & \multicolumn{2}{|c|}{ Missouri Network } & \multicolumn{2}{|c|}{ AAFP National Network } \\
\hline & $\begin{array}{l}\text { Single Question } \\
\text { No. (\%) }\end{array}$ & $\begin{array}{l}\text { CAGE Questions } \\
\text { No. (\%) }\end{array}$ & $\begin{array}{l}\text { Single Question } \\
\text { No. (\%) }\end{array}$ & $\begin{array}{l}\text { CAGE Questions } \\
\text { No. (\%) }\end{array}$ \\
\hline \multicolumn{5}{|l|}{ Precontemplation } \\
\hline "I don't drink. " & $7(5)$ & $5(5)$ & $3(8)$ & 0 \\
\hline $\begin{array}{l}\text { "I don't plan to change my drinking pattern } \\
\text { because it is not a problem for me." }\end{array}$ & $76(53)$ & $62(60)$ & $19(48)$ & $16(48)$ \\
\hline \multicolumn{5}{|l|}{ Contemplation } \\
\hline $\begin{array}{l}\text { "I don't plan to change my drinking pattern } \\
\text { even though it may be a problem for me." }\end{array}$ & $7(5)$ & $4(4)$ & $2(5)$ & \\
\hline "I'll think about my drinking pattern." & $16(11)$ & $8(8)$ & $4(10)$ & $3(9)$ \\
\hline \multicolumn{5}{|l|}{ Planning } \\
\hline "I'll keep track of how much I drink." & $13(9)$ & $6(6)$ & $3(8)$ & $3(9)$ \\
\hline \multicolumn{5}{|l|}{ Action } \\
\hline "I'll cut down on my drinking." & $17(12)$ & $14(14)$ & $6(15)$ & $7(21)$ \\
\hline "I'll quit drinking." & $3(2)$ & $2(2)$ & $1(3)$ & $2(6)$ \\
\hline \multicolumn{5}{|l|}{ Maintenance } \\
\hline "I'm a recovering alcoholic." & $5(3)$ & $2(2)$ & & $1(3)$ \\
\hline Missing data & & & $2(5)$ & $1(3)$ \\
\hline Total & 144 & 103 & 40 & 33 \\
\hline
\end{tabular}

alcohol problems, the prevalence was $12 \%$ in the AAFP network and $17 \%$ in Missouri. The 2 screening approaches had similar sensitivity and specificity in both networks. In the AAFP network, the sensitivity and specificity were $70 \%$ and $90 \%$, respectively, for the lifetime CAGE, $42 \%$ and $98 \%$, respectively, for the past-year CAGE, and $63 \%$ and $94 \%$, respectively, for the single question. In Missouri, the sensitivity and specificity were $60 \%$ and $88 \%$, respectively, for the lifetime CAGE, and $76 \%$ and $91 \%$, respectively, for the single question.

\section{Clinician Intervention and Patients' Engagement in Change}

Clinicians reported "doing 'something' (anything) about the patient's drinking problem" with $20 \%$ of those who had a positive CAGE response and with $27 \%$ who had a positive single question response in Missouri, and with $24 \%$ and $38 \%$, respectively, in the AAFP network. Combining the 2 networks, clinicians addressed the issue with $21 \%$ of patients with an AUDIT of 5 or greater and $30 \%$ of those with an AUDIT of 8 or greater.

On the patient questionnaire, completed after the encounter, patients were asked to "Circle the [answer] that best describes what you will do in the next month with regard to alcohol use." Among patients with an AUDIT score of 5 or greater, about one third reported planning to "think about my drinking pattern," cut down, or quit drinking (Table 4). There was no significant difference between screening approaches in this response in either network.

\section{DISCUSSION}

The CAGE questions and the single question were equivalent by most measures examined. Clinicians in Missouri were significantly more likely to use the single question when it was the assigned screening approach ( $81 \%$ of encounters) than the CAGE questions (69\%, $P$ $=.001)$, but we found no such difference in the AAFP network. The difference between the 2 networks may be due to some Missouri clinicians' having participated in previous studies of the single question, perhaps leading to greater comfort with it. In the AAFP network, clinicians screened almost every patient regardless of assigned approach, and their enthusiasm for data collection may have hindered the study's ability to find a difference between the 2 approaches.

Neither screening approach was superior to the other in self-reported patient or clinician comfort. Most patients, including most of those with possible alcohol problems (judging by a positive AUDIT finding), were comfortable with either approach. Furthermore, clinicians did not sense any difference between approaches in how open patients were to discussing alcohol.

More than $80 \%$ of the alcohol-related discussions 
lasted less than 1 minute. Although less time was spent when the single question rather than the CAGE screening tool was used, the difference was neither clinically nor statistically significant. Compared with patients without alcohol problems, clinicians spent more time discussing alcohol with problem drinkers, but again the difference was small. Even with problem drinkers, most alcohol-related discussions lasted less than 1 minute.

The 2 screening approaches were equally engaging for problem drinkers. With either approach, about one half of the patients with an AUDIT score of 5 or greater did not see their drinking as a problem, but one third of them were contemplating or planning change. We have only self-reported plans, not self-reported drinking outcomes, and it is unlikely that all those who reported such plans followed through with them. Some patients who were not screened reported plans for change. We therefore cannot conclude that either screening approach moved patients toward change, but only that the 2 approaches are similar in this regard. That a substantial minority is considering change, however, may help alleviate the concern about imposing an alcohol discussion when it's not on the patient's agenda. ${ }^{16}$

Determining the sensitivity and specificity of the 2 screening approaches was not a primary aim of the study, and the criterion standard we used in our analyses was another screening instrument (the AUDIT). We chose the AUDIT because of its suitability for quick, anonymous self-reporting. Its sensitivity and specificity may be higher than those of other screening instruments. ${ }^{24}$ In comparison with the AUDIT, the performance of the CAGE and the single question was similar in our study. When focused on just the past year, the sensitivity of the CAGE questions was less than when the frame of reference was lifetime (42\% vs $70 \%)$, and the specificity was higher (98\% vs 90\%). Bradley and her colleagues found a similar pattern, with sensitivities of $57 \%$ and $77 \%$ and specificities of $82 \%$ and $59 \%$ with past-year and lifetime frames of reference, respectively. ${ }^{21}$

Although the number of encounters was large $(2,800)$, clinicians $(\mathrm{N}=44)$ were the unit of randomization. Cluster-randomized trials have less statistical power than the number of individual patients involved suggests. ${ }^{25}$ The differences between screening approaches were small, however, and the 95\% confidence intervals generally excluded a clinically meaningful difference.

Clinicians intervened in some way with fewer than $30 \%$ of the identified problem drinkers. We did not define what constituted an appropriate intervention, and some clinicians may have helped some patients move toward change without realizing they were providing an intervention. Had clinicians provided a longer intervention, however, patients' self-reported engagement in thinking about or planning to change their alcohol use might have differed more between the 2 screening approaches. Longer interventions would not necessarily have helped more patients move toward change, but with longer interventions, one screening approach might have been associated with greater selfreported interest in change by patients.

Participating clinicians volunteered for the study. They may have had special interest in alcohol issues or health behavior more broadly. The results, therefore, might not apply to all clinicians or practice settings. Even so, the results do suggest that both screening approaches are equally comfortable and engaging from the patients' perspective, leaving the choice of screening approach open to the clinician. Furthermore, a substantial minority of problem drinkers reported planning to think about or change their drinking behavior, suggesting that routine screening in primary care practice may be beneficial.

To read or post commentaries in response to this article, see it online at http://www.annfammed.org/cgi/content/full/2/5/398.

Key words: Drinking behavior; alcohol drinking; alcohol-induced disorders/diagnosis; mass screening; patient acceptance of health care

Submitted April 7, 2003; submitted, revised, July 8, 2003; accepted August 8, 2003.

Funding support: Funded by grants from the Alcoholic Beverage Medical Research Foundation and from the American Academy of Family Physicians Foundation.

Acknowledgments: Our thanks to Ms. Sandy Taylor who designed the data collection forms.

Study participants. Missouri: Jeffrey Belden, MD; Carole Silney, MD; Bridget Early, MD; Andrew Quint, MD; Robert Buffaloe, MD; William Rice, DO; Edith Daniel, RNCS-FNP; Jim Elam, MD; Dennis Handley, MD; Robert Koch, MD; Deborah Johnoff, RNCS-FNP; Cynthia Ruffolo, MD; Monika Prost, MD; Rebecca Kelley, MD; William Kimlinger, MD; Kenneth Ogawa, M; Julie Wood, MD; Joseph Quaranto, DO; Abbe Sudvarg, MD. University of Missouri-Columbia: Robert Bynum, DO; Sarah McElroy, MD; Lynn Wung, MD; Joseph Beckmann, MD; Paul Schoephoerster, MD; Tony Cook, FNP, and colleagues; James Stevermer, MD, and colleagues; Susan Even, MD, and colleagues; Anne Fitzsimmons, MD, and colleagues; Larry Rues, MD, and colleagues.

\section{References}

1. Centers for Disease Control and Prevention. Behavioral risk factor surveillance system online prevalence data. Atlanta, Ga: Division of Adult and Community Health, National Center for Chronic Disease Prevention and Health Promotion, Centers for Disease Control and Prevention; 1999. Available at: http://www.cdc.gov/brfss/ti-surveydata1999.htm.

2. American Psychiatric Association. Substance-Related Disorders. Diagnostic and Statistical Manual of Mental Disorders. 4th ed. Washington, DC: American Psychiatric Association; 1994:175-204.

3. Grant BF, Harford TC, Dawson DA, Chou P, Dufour M, Pickering R. Prevalence of DSM-IV alcohol abuse and dependence: United States, 1992. Alcohol Health Res World. 1994;18:243-248. 
4. Wilk Al, Jensen NM, Havighurst TC. Meta-analysis of randomized control trials addressing brief interventions in heavy alcohol drinkers. J Gen Intern Med. 1997;12:274-283.

5. Fleming MF, Barry KL, Manwell LB, Johnson K, London R. Brief physician advice for problem alcohol drinkers: a randomized controlled trial in community-based primary care practices. JAMA. 1997;277:1039-1044.

6. Fleming MF, Mundt MP, French MT, Manwell LB, Stauffacher EA, Barry KL. Brief physician advice for problem drinkers: long-term efficacy and benefit-cost analysis. Alcohol Clin Exp Res. 2002;26:36-43.

7. National Institute on Alcohol Abuse and Alcoholism. The physician's guide to helping patients with alcohol problems. Bethesda, Md: National Institutes of Health; 1995. Available at: http://www.niaaa. nih.gov/publications/physicn.htm.

8. U.S. Preventive Services Task Force. Guide to Clinical Preventive Services: Report of the U.S. Preventive Services Task Force. 2nd ed. Baltimore, Md: Williams \& Wilkins; 1996.

9. Allen JP, Maisto SA, Connors GJ. Self-report screening tests for alcoho problems in primary care. Arch Intern Med. 1995;155:1726-1730.

10. Buchsbaum DG, Buchanan RG, Centor RM, Schnoll SH, Lawton MJ. Screening for alcohol abuse using CAGE scores and likelihood ratios. Ann Intern Med. 1991;115:774-777.

11. Williams $\mathrm{RH}$, Vinson DC. Validation of a single question screen for problem drinking. J Fam Pract. 2001;50:307-312.

12. Vinson DC, Elder NC, Werner JJ, Vorel LA, Nutting PA. Alcoholrelated discussions in primary care: a report from ASPN. J Fam Pract. 2000:49:28-33.

13. Bradley KA, Curry SJ, Koepsell TD, Larson EB. Primary and secondary prevention of alcohol problems: U.S. internist attitudes and prac tices. J Gen Intern Med. 1995;10:67-72.

14. Wenrich MD, Paauw DS, Carline JD, Curtis JR, Ramsey PG. Do primary care physicians screen patients about alcohol intake using the CAGE questions? J Gen Intern Med. 1995;10:631-634.

15. Miller NS, Sheppard L, Colenda CC, Magen J. Why physicians are unprepared to treat patients who have alcohol- and drug-related disorders. Acad Med. 2001;7:410-418.
16. Rush BR, Powell LY, Crowe TG, Ellis K. Early intervention for alcohol use: family physicians' motivations and perceived barriers. Can Med Assoc J. 1995;152:863-869.

17. Kaplan SH, Greenfield S, Ware JE Jr. Assessing the effects of physician-patient interactions on the outcomes of chronic disease. Med Care. 1989;27:S110-S127.

18. Miller WR, Benefield RG, Tonigan JS. Enhancing motivation for change in problem drinking: a controlled comparison of two therapist styles. J Consult Clin Psychol. 1993;61:455-461.

19. Steinweg DL, Worth H. Alcoholism: the keys to the CAGE. Am J Med. 1993;94:520-523.

20. Friedmann PD, Zhang JX, Pittinger C, Brooks AR, Saitz R. Does an open-ended introduction or question order influence the test characteristics of alcohol screening tools? Subst Abuse. 2000;21:48-49.

21. Bradley KA, Kivlahan DR, Bush KR, McDonell MB, Fihn SD. Variations on the CAGE alcohol screening questionnaire: strengths and limitations in VA general medical patients. Alcohol Clin Exp Res. 2001:25:1472-1478.

22. Ewing JA. Detecting alcoholism: the CAGE questionnaire. JAMA. 1984;252:1905-1907.

23. Saunders JB, Aasland OG, Babor TF, de la Fuente JR, Grant M. Development of the Alcohol Use Disorders Identification Test (AUDIT): WHO collaborative project on early detection of persons with harmful alcohol consumption--Il. Addiction. 1993:88:791-804.

24. Reinert DF, Allen JP. The Alcohol Use Disorders Identification Test (AUDIT): a review of recent research. Alcohol Clin Exp Res. 2002:26:272-279.

25. Kerry SM, Bland JM. Analysis of a trial randomised in clusters. BMJ. 1998;316:54.

26. Stata Corporation. Stata Statistical Software. College Station, Tx: Stata Corporation: 1999.

27. DiClemente CC, Prochaska JO. Toward a comprehensive, transtheoretical model of change: stages of change and addictive behaviors. In: Miller WR, Heather N, eds. Treating Addictive Behaviors. 2nd ed. New York, NY: Plenum Press; 1998:3-24. 